\title{
c-Src-dependent EGF receptor transactivation contributes to ET-1-induced COX-2 expression in brain microvascular endothelial cells
}

\author{
Hsi-Lung Hsieh ${ }^{1 \dagger}$, Chih-Chung Lin ${ }^{2 \dagger}$, Hui-Ju Chan ${ }^{3}$, Caleb M Yang ${ }^{4}$ and Chuen-Mao Yang ${ }^{3,5^{*}}$
}

\begin{abstract}
Background: Endothelin-1 (ET-1) is elevated and participates in the regulation of several brain inflammatory disorders. The deleterious effects of ET-1 on endothelial cells may aggravate brain inflammation mediated through the upregulation of cyclooxygenase-2 (COX-2) gene expression. However, the signaling mechanisms underlying ET-1-induced COX-2 expression in brain microvascular endothelial cells remain unclear.
\end{abstract}

Objective: The goal of this study was to examine whether ET-1-induced COX-2 expression and prostaglandin $E_{2}$ $\left(\mathrm{PGE}_{2}\right)$ release were mediated through a c-Src-dependent transactivation of epidermal growth factor receptor (EGFR) pathway in brain microvascular endothelial cells (bEnd.3 cells).

Methods: The expression of COX-2 induced by ET-1 was evaluated by Western blotting and RT-PCR analysis. The COX-2 regulatory signaling pathways were investigated by pretreatment with pharmacological inhibitors, short hairpin RNA (shRNA) or small interfering RNA (siRNA) transfection, chromatin immunoprecipitation (ChIP), and promoter activity reporter assays. Finally, we determined the $\mathrm{PGE}_{2}$ level as a marker of functional activity of COX-2 expression.

Results: First, the data showed that ET-1-induced COX-2 expression was mediated through a c-Src-dependent transactivation of EGFR/PI3K/Akt cascade. Next, we demonstrated that ET-1 stimulated activation (phosphorylation) of c-Src/EGFR/Akt/MAPKs (ERK1/2, p38 MAPK, and JNK1/2) and then activated the c-Jun /activator protein 1 (AP-1) via $G_{q / i}$ protein-coupled $\mathrm{ET}_{\mathrm{B}}$ receptors. The activated c-Jun/AP-1 bound to its corresponding binding sites within COX-2 promoter, thereby turning on COX-2 gene transcription. Ultimately, upregulation of COX-2 by ET-1 promoted PGE 2 biosynthesis and release in bEnd.3 cells.

Conclusions: These results demonstrate that in bEnd.3 cells, c-Src-dependent transactivation of EGFR/PI3K/Akt and MAPKs linking to c-Jun/AP-1 cascade is essential for ET-1-induced COX-2 upregulation. Understanding the

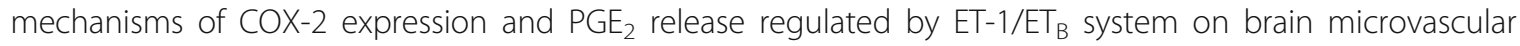
endothelial cells may provide rational therapeutic interventions for brain injury and inflammatory diseases.

\section{Background}

Cyclooxygenase (COX) is a rate-limiting key enzyme in the synthesis of prostaglandins (PGs) and thromboxane. In this process, phospholipase $\mathrm{A}_{2}$ catalyzes the release of arachidonic acid (AA) from membrane phospholipids, while $\mathrm{COX}$ catalyzes the conversion of $\mathrm{AA}$ into $\mathrm{PGH}_{2}$,

\footnotetext{
* Correspondence: chuenmao@mail.cgu.edu.tw

${ }^{\dagger}$ Equal contributors

${ }^{3}$ Department of Physiology and Pharmacology, and Health Aging Research Center, College of Medicine, Chang Gung University, Tao-Yuan, Taiwan ${ }^{5}$ Department of Pharmacology, Chang Gung University, 259 Wen-Hwa 1st Road, Kwei-San, Tao-Yuan, Taiwan

Full list of author information is available at the end of the article
}

which is the common precursor of all prostanoids [1,2]. Two COX isoforms have been demonstrated: COX-1, which is constitutively expressed in most tissues, regulates normal physiological responses and controls renal and vascular homeostasis; COX-2, another COX isoform, is not detectable in most normal tissues or resting cells, but its expression can be induced by various stimuli, including cytokines, endotoxin, and growth factors to produce proinflammatory PGs during inflammatory responses in several cell types including vascular endothelial and smooth muscle cells [3,4]. Previous studies have shown that COX-2 immunoreactivity is detected in 
various inflammatory tissues, including synovial macrophage and vascular cells of patients with arthritis and atherosclerosis, respectively. Several lines of evidence have further confirmed COX-2 as a major therapeutic target for the treatment of inflammatory disorders such as arthritis [1]. Moreover, homozygous deletion of the COX-2 gene in mice leads to a striking reduction of endotoxin-induced inflammation [5]. Therefore, COX-2 may play an important role in the development of various inflammatory responses such as vascular inflammation (i.e., atherosclerosis and hypertension). In brain, upregulation of COX-2 leads to increased production of PGs, which are potent inflammatory mediators associated with neurodegenerative disorders [6]. Thus, COX2 and its metabolites PGs may act as a major pathological factor in brain inflammatory diseases.

The endothelium plays an important role in the regulation of vascular function by producing a large number of biologically active substances that participate in the regulation of vascular functions. In brain, cerebral capillary and microvascular endothelial cells play an active role in maintaining cerebral blood flow, microvascular tone, and blood-brain barrier (BBB) functions [7]. Dysfunction of the vascular endothelium is an early finding in the development of various vascular diseases and is closely related to clinical events in patients with atherosclerosis and hypertension [8,9]. Endothelial cells are known to produce vasoactive mediators such as endothelin (ET) to maintain hemodynamic responses. Among the ET family, the bioactivity of ET-1 is mediated through potent vasoconstrictor and proinflammatory action, and has been implicated in the pathogenesis of hypertension and vascular diseases [9-11]. Two types of ET receptors, ET type $\mathrm{A}\left(\mathrm{ET}_{\mathrm{A}}\right)$ and type $\mathrm{B}$ $\left(\mathrm{ET}_{\mathrm{B}}\right)$, are responsible for ET-1-triggered biological effects, which are mediated via $G$ protein-dependent regulation [12]. In the central nervous system (CNS), ET-1 also plays a substantial role in the normal development or in CNS diseases. Both endothelial cells [13] and astrocytes [14] are potential sources of ET-1 release in response to hypoxic/ischemic injury of the brain. The $\mathrm{ET}_{\mathrm{B}}$ receptors are located on both endothelial and vascular smooth muscle cells, and modulate post-injury responses of these cells in the CNS [11]. There has been an increasing interest in the regulatory role of endothelial cells in neurovascular coupling, which matches an adequate supply of cerebral blood flow with the local metabolic demands that are imposed by neural activity [15]. As a fundamental component of the neurovascular unit, endothelium dysfunction has been implicated in neurodegenerative diseases $[15,16]$. Circumstantial evidence has further demonstrated that overexpression of ET-1 on endothelial cells has deleterious effects on ischemic brain [7]. Endothelial ET-1 can induce cytokine or chemokine (e.g., interleukin-1 or interleukin-8) production and secretion by non-neuronal cells, including astrocytes and endothelial cells, which directly contribute to BBB breakdown during CNS inflammation [17]. These findings imply the involvement of ET-1 in neuroinflammation in the CNS. However, the detailed mechanisms responsible for ET-1 action remain unclear.

ET-1 activates multiple signaling pathways and regulates diverse cellular functions via $\mathrm{ET}$ receptors $\left(\mathrm{ET}_{\mathrm{A}}\right.$ or $\mathrm{ET}_{\mathrm{B}}$ ), which couple to various $G$ proteins such as $\mathrm{G}_{\mathrm{q}}$ and $\mathrm{G}_{\mathrm{i}}[12,18-20]$. The principal mechanism underlying activation by ET-1 is mediated through $\mathrm{ET}_{\mathrm{B}}$ receptors coupling $G_{q}$ proteins, resulting in activation of phospholipase $C$ (PLC)- $\beta$, phosphoinositide (PI) hydrolysis, and formation of inositol trisphosphate $\left(\mathrm{IP}_{3}\right)$ and diacylglycerol, leading to $\mathrm{Ca}^{2+}$ increase and protein kinase $\mathrm{C}$ (PKC) activation [21]. Activation of $\mathrm{ET}_{\mathrm{B}}$ receptor has been also shown to inhibit adenylyl cyclase via coupling to $G_{i}$ proteins [22]. Several lines of evidence demonstrate that mitogen-activated protein kinases (MAPKs) could be activated by the activation of $G_{q}$ and $G_{i}$ protein-coupled receptors via different signal pathways [23]. MAPKs activation by ET-1 has been shown to modulate various cellular responses, including cellular hypertrophy, growth, proliferation, and cell survival in various cell types $[19,24]$. Induction of COX-2 expression requires activation of MAPK and stimulation of particular transcription factors in various cell types $[20,25,26]$. Moreover, it has been shown that signaling through MAPKs, extracellular signal-regulated protein kinase $1 / 2$ (ERK1/2) especially, in response to GPCR agonists can be mediated through transactivation of the epidermal growth factor receptor (EGFR) [27]. The transactivation of EGFR by GPCRs mediated by activation of non-receptor tyrosine kinases such as the Src family or release of heparin-binding EGFlike growth factor (HB-EGF) has been demonstrated in various cell types [28]. ET-1 has also been shown to share this transactivation of EGFR in ovarian cancer cells or VSMCs, leading to MAPK activation and then regulating cell proliferation or COX-2 expression, respectively $[29,30]$. Our previous report demonstrated that bradykinin stimulates ERK1/2 activation and cell proliferation via Src family kinases and EGFR transactivation in VSMCs [31]. Additionally, ET-1 can stimulate transactivation of EGFR via $\mathrm{ET}_{\mathrm{A}}$ receptors in rat cardiac fibroblasts [32]. Several previous reports have also demonstrated that GPCR agonists (e.g., sphingosine 1phosphate and thrombin) stimulate ERK1/2 phosphorylation and AP-1 activation associated with COX-2 expression in rat VSMCs $[4,31]$. However, several reports have demonstrated that proinflammatory stimuli, which play a critical role in inflammation, rapidly upregulate AP-1dependent genes such as COX-2 [33-35]. In brain microvascular endothelial cells, the mechanisms underlying 
ET-1-induced COX-2 expression and $\mathrm{PGE}_{2}$ production are not completely defined, the c-Src-dependent transactivation of EGFR cascade especially.

In this study, we investigated the molecular mechanisms underlying ET-1-induced COX-2 expression in mouse brain microvascular endothelial (bEnd.3) cells. These findings suggested that ET-1 induces COX-2 expression at the transcriptional and translational levels, which is mediated through the $\mathrm{ET}_{\mathrm{B}}$ receptor (coupling to $G_{i}$ and $G_{q}$ )-mediated $c$-Src-dependent transactivation of EGFR and activation of PI3K/Akt, ERK1/2, p38 MAPK, JNK1/2, and c-Jun/AP-1 pathways, leading to $\mathrm{PGE}_{2}$ biosynthesis in mouse bEnd. 3 cells. These results provide new insights into the mechanisms of ET-1 action, which may be therapeutic targets in brain inflammatory diseases.

\section{Methods}

\section{Materials}

Dulbecco's modified Eagle's medium (DMEM)/F-12 medium, fetal bovine serum (FBS), and TRIzol were from Invitrogen (Carlsbad, CA). The Hybond C membrane and enhanced chemiluminescence (ECL) Western blot detection system were from GE Healthcare Biosciences (Buckinghamshire, UK). Anti-COX-2 monoclonal antibody was from BD Transduction Laboratories (San Diego, CA). Phospho-c-Src (\#2120), Phospho-EGFR (\#2231), Phospho-Akt (\#9271), Phospho-ERK1/2 (\#9101), Phospho-p38 (\#9211), Phospho-JNK1/2 (\#9255), and Phospho-c-Jun (\#2361) antibodies were from Cell Signaling (Danver, MA). c-Src (sc-8056), EGFR (sc-03), p85 (sc423), Akt (sc-8312), and c-Jun (sc-1694) antibodies were from Santa Cruz (Santa Cruz, CA). Anti-glyceraldehyde3-phosphate dehydrogenase (GAPDH, cat. no. 46999555) antibody was from Biogenesis (Boumemouth, UK). Genistein, PP1, AG1478, LY294002, SH-5, BQ-123, BQ-788, GP antagonist-2, GP antagonist-2A, U0126, SB202190, SP600125, and tanshinone IIA were from Biomol (Plymouth Meeting, PA). Bicinchoninic acid (BCA) protein assay reagent was from Pierce (Rockford, IL). Enzymes, ET-1, and other chemicals were from Sigma (St. Louis, MO).

\section{Mouse brain microvascular endothelial cell culture}

Mouse brain microvascular endothelial cells (bEnd.3) were purchased from Bioresource Collection and Research Centre (BCRC, Hsinchu, Taiwan) and were grown in DMEM/F-12 containing 10\% FBS and antibiotics (100 $\mathrm{U} / \mathrm{ml}$ penicillin $\mathrm{G}, 100 \mu \mathrm{g} / \mathrm{ml}$ streptomycin, and $250 \mathrm{ng} /$ $\mathrm{ml}$ fungizone) at $37{ }^{\circ} \mathrm{C}$ in a humidified $5 \% \mathrm{CO}_{2}$ atmosphere. When the cultures had grown to confluence, cells were released with $0.05 \%(\mathrm{w} / \mathrm{v})$ trypsin $/ 0.53 \mathrm{mM}$ EDTA for $5 \mathrm{~min}$ at $37{ }^{\circ} \mathrm{C}$. The cell suspension was diluted with DMEM/F-12 containing 10\% FBS to a concentration of
$2 \times 10^{5}$ cells $/ \mathrm{ml}$. The cell suspension was plated onto 6 well culture plates $(2 \mathrm{ml} /$ well $)$ or $10-\mathrm{cm}$ culture dishes $(10 \mathrm{ml} / \mathrm{dish})$ for the measurement of protein or RNA expression, respectively. Culture medium was changed after $24 \mathrm{~h}$ and then every 3 days. Experiments were performed with cells from passages 5 to 13 .

\section{Preparation of cell extracts and Western blot analysis}

Growth-arrested cells were incubated with ET-1 at $37{ }^{\circ} \mathrm{C}$ for various time intervals. The cells were washed with ice-cold phosphate-buffered saline (PBS), scraped, and collected by centrifugation at $45,000 \times \mathrm{g}$ for $1 \mathrm{~h}$ at $4{ }^{\circ} \mathrm{C}$ to yield the whole cell extract, as described previously [4]. Samples were denatured, subjected to SDS-PAGE using a $10 \%(\mathrm{w} / \mathrm{v})$ running gel, and transferred to nitrocellulose membrane. Membranes were incubated overnight using an anti-COX-2, Phospho-c-Src, PhosphoEGFR, Phospho-Akt, Phospho-ERK1/2, Phospho-p38, Phospho-JNK1/2, and Phospho-c-Jun, c-Src, EGFR, p85, Akt, c-Jun, or GAPDH antibody (1:1,000 dilution). Membranes were washed with TTBS four times for 5 min each, incubated with a 1:2,000 dilution of antirabbit horseradish peroxidase antibody for $1 \mathrm{~h}$. The immunoreactive bands were detected by ECL reagents.

\section{Total RNA extraction and gene expression}

For reverse transcription PCR (RT-PCR) analysis, total RNA was extracted from mouse brain endothelial cells stimulated by ET-1, as previously described [4]. The cDNA obtained from $0.5 \mu \mathrm{g}$ total RNA was used as a template for PCR amplification. Oligonucleotide primers were designed based on Genbank entries for mouse COX-2 and $\beta$-actin. The following primers were used for amplification reaction: for COX-2: 5' (AAAACCGTGGGGAATGTATGAGC)-3' (sense), 5' (GATGGGTGAAGTGCTGGGGAAAG)-3' (anti-sense); for $\beta$-actin: $5^{\prime}$-(GAACCCTAAGGCCAACCGTG)-3' (sense), 5' -(TGGCATAGAGGTCTTTACGG)-3' (antisense). PCR mixes contained $10 \mu \mathrm{l}$ of $5 \times$ PCR buffer, $1.25 \mathrm{mM}$ of each dNTP, 100 pmol of each forward and reverse primer, and 2.5 units of Taq polymerase (Takara, Shiga, Japan). The final reaction volume was $50 \mu \mathrm{l}$. Amplification was performed in 25 cycles at 94 ${ }^{\circ} \mathrm{C}, 20 \mathrm{~s} ; 60{ }^{\circ} \mathrm{C}, 40 \mathrm{~s} ; 72{ }^{\circ} \mathrm{C}, 40 \mathrm{~s}$ [36]. After the last cycle, all samples were incubated for an additional 10 min at $72{ }^{\circ} \mathrm{C}$. PCR fragments were analyzed on $2 \%$ agarose $1 \times$ TAE gel containing ethidium bromide, and their size was compared to a molecular weight marker. Amplification of $\beta$-actin, a relatively invariant internal reference RNA, was performed in parallel, and cDNA amounts were standardized to equivalent $\beta$-actin mRNA levels. These primer sets specifically recognized only the genes of interest as indicated by amplification of a single band of the expected size (500 bp for 
COX-2 and 514 bp for $\beta$-actin) and direct sequence analysis of the PCR products.

\section{Plasmid construction, transient transfection, and luciferase assays}

The mouse COX-2 promoter was constructed as described previously [37] with some modifications. The upstream region $(-907$ to +70$)$ of the mouse COX-2 promoter was cloned to the pGL3-basic vector containing the luciferase reporter system. Introduction of a double-point mutation into the AP-1-binding site (ACAGTCA to ACAACCA) to generate pGL-COX2mAP1 was performed using the following (forward) primer: 5'-GGTACCGACGTACAGACCAGACACGG-3'. The underlined nucleotides indicate the positions of substituted bases. The mutant construct was cloned into the pGL3-basic vector containing the luciferase reporter system. All plasmids were prepared by using QIAGEN plasmid DNA preparation kits. The shRNA for c-Src, EGFR, p85, and Akt was provided by Dr. C.P. Tseng (Chang Gung University). The siRNAs for c-Jun and scrambled control were from Dharmacon Research Inc. (Lafayette, CO, USA), and AP-1-promoter or COX-2 promoter reporter construct was transfected into cells using the Lipofetamine-2000 transfection reagent according to the manufacturer's instructions (Invitrogen, Carlsbad, CA). The transfection efficiency ( 60\%) was determined by transfection with enhanced EGFP. To assess promoter activity, cells were collected and disrupted by sonication in lysis buffer (25 mM Tris-phosphate, $\mathrm{pH}$ 7.8, 2 mM EDTA, 1\% Triton X-100, and 10\% glycerol). After centrifugation, aliquots of the supernatants were tested for luciferase activity using a luciferase assay system. Firefly luciferase activities were standardized to $\beta$ galactosidase activity.

\section{Chromatin immunoprecipitation (ChIP) assay}

The assay was performed as described previously [38] with modifications. In brief, bEnd. 3 cells were cross-linked with $1 \%$ formaldehyde for $10 \mathrm{~min}$ at $37{ }^{\circ} \mathrm{C}$ and washed three times with ice-cold PBS containing $1 \mathrm{mM}$ phenylmethylsulfonyl fluoride (PMSF) and 1\% aprotinin. Soluble chromatin was prepared using a ChIP assay kit (Upstate) according to the manufacturer's recommendations, and immunoprecipitated without (control) or with anti-c-Jun antibody and normal goat immunoglobulin G (IgG). Following washes and elution, precipitates were heated overnight at $65^{\circ} \mathrm{C}$ to reverse cross-linking of DNA and protein. DNA fragments were purified by phenol-chloroform extraction and ethanol precipitation. The purified DNA was subjected to PCR amplification using the primers specific for the region $(-371$ to +70$)$ containing AP-1-binding domain present in the COX-2 promoter, sense primer: $5^{\prime}$ GGGGGAGGGAAGCTGTGACACTCTTGAGCTTT-3' antisense primer: 5'-GACAGTGCTGAGATTCTTCGTGAGCAGAGTCC-3'. PCR fragments were analyzed on $2 \%$ agarose $1 \times$ TAE gel containing ethidium bromide, and the size (440 bp) was compared to a molecular weight marker.

\section{Measurement of $\mathrm{PGE}_{2}$ release}

The cells were seeded in 12-well plates and grown to confluence. Cells were shifted to serum-free DMEM/F12 medium for $24 \mathrm{~h}$, and then treated with ET-1 for various time intervals. The culture supernatants were collected to measure $\mathrm{PGE}_{2}$ levels using an EIA kit as specified by the manufacturer (Cayman Chemical).

\section{Analysis of data}

All data were estimated using GraphPad Prism Program (GraphPad, San Diego, CA). Quantitative data were analyzed by one-way ANOVA followed by Tukey's honestly significant difference tests between individual groups. Data were expressed as mean \pm SEM. A value of $P<0.05$ was considered significant.

\section{Results}

The c-Src tyrosine kinase mediates ET-1-induced COX-2 expression in bEnd. 3 cells

It has been well established that cytoplasmic tyrosine kinases of the c-Src family are involved in signaling events evoked by G protein-coupled receptors (GPCRs), which modulate many cellular functions. To determine whether c-Src is involved in ET-1-induced COX-2 expression in bEnd. 3 cells, a pan-protein tyrosine kinases inhibitor genistein and a selective pharmacological inhibitor of c-Src were used. As shown in Figure 1A-D, pretreatment with genistein (Gen) or PP1 for $1 \mathrm{~h}$ prior to exposure to ET-1 for 6 or $1 \mathrm{~h}$ concentrationdependently blocked ET-1-induced COX-2 protein or mRNA expression. To further demonstrate whether ET1 stimulates phosphorylation of c-Src, which is involved in these responses, as shown in Figure 1E, ET-1 stimulated a time-dependent phosphorylation of c-Src with a maximal response within $30 \mathrm{~s}$ in bEnd. 3 cells. Pretreatment with PP1 (100 nM) significantly attenuated ET-1stimulated phosphorylation of $\mathrm{c}$-Src during the period of observation. To further ensure the involvement of c-Src in ET-1-induced COX-2 expression, transfection of cells with c-Src shRNA downregulated the total c-Src protein and attenuated ET-1-induced COX-2 expression (Figure 1F). The results demonstrated that ET-1-induced COX-2 expression is mediated through a c-Srcdependent pathway in bEnd.3 cells.

\section{ET-1 induces COX-2 expression via transactivation of EGFR}

Cross-talk between GPCRs and RTKs has been shown to regulate the expression of several target proteins in 


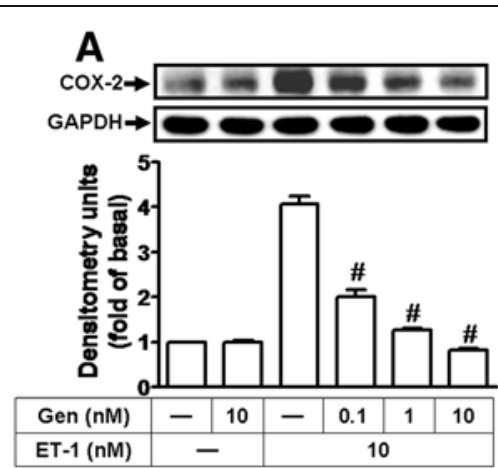

B

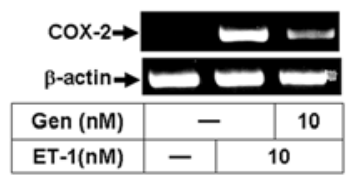

\section{E}

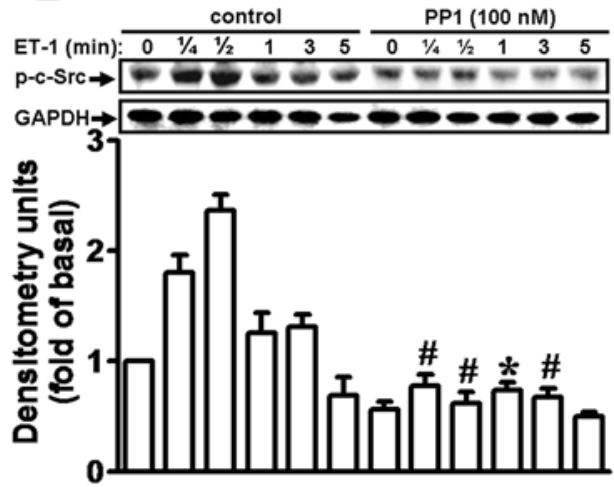

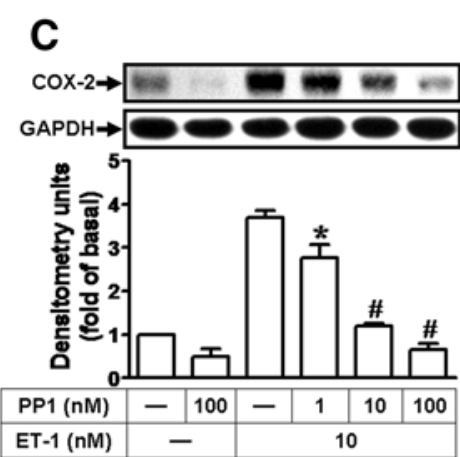
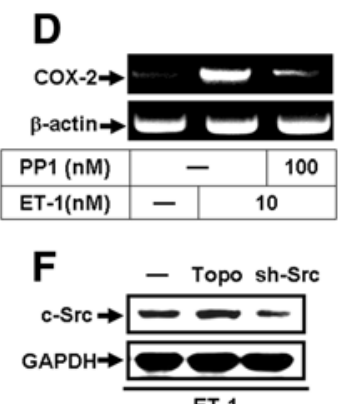

ET-1

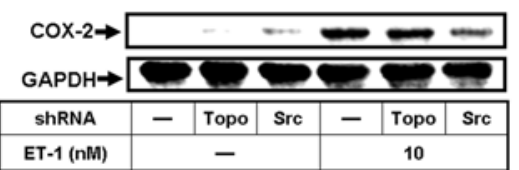

Figure 1 ET-1 induces COX-2 expression via c-Src tyrosine kinase in bEnd.3 cells. (A,B) Involvement of protein tyrosine kinases in ET-1induced COX-2 expression; cells were pretreated with various concentrations of genistein $(0.1,1$, or $10 \mathrm{nM})$ for $1 \mathrm{~h}$ and incubated with $10 \mathrm{nM}$ ET1 for $6 \mathrm{~h}(\mathbf{A})$ or $1 \mathrm{~h}(\mathbf{B})$. (C,D) Involvement of c-Src tyrosine kinase in ET-1-induced COX-2 expression; cells were pretreated with various concentrations of PP1 (1, 10, or $100 \mathrm{nM})$ for $1 \mathrm{~h}$ and incubated with $10 \mathrm{nM}$ ET-1 for $6 \mathrm{~h}$ (C) or $1 \mathrm{~h} \mathrm{(D)}$. (E) Time dependence of ET-1-induced c-Src phosphorylation; cells were treated with $10 \mathrm{nM}$ ET-1 for the indicated time intervals in the presence or absence of PP1 (100 nM). The phosphorylation of c-Src was analyzed by Western blot using an anti-phospho-c-Src antibody. (F) Cells were transfected with shRNA of c-Src (shSrc) for $24 \mathrm{~h}$ (Topo: as a control) and treated with $10 \mathrm{nM}$ ET-1 for $6 \mathrm{~h}$. The COX-2 protein $(\mathbf{A}, \mathbf{C}, \mathbf{F})$ and mRNA (B,D) were analyzed by Western blotting and RT-PCR, respectively. Data are expressed as mean \pm SEM of three individual experiments $(n=3) .{ }^{*} P<0.05,{ }^{\#} P<0.01$ as compared with cells stimulated by ET-1 alone.

various cell types. It has been reported that transactivation of RTKs, EGFR especially, mediates signalings activated by GPCR ligands, such as ET-1, lysophosphatidic acid, and bradykinin [27,39]. To examine whether RTK transactivation is required for ET-1-induced COX-2 expression, as shown in Figure $2 \mathrm{~A}$ and $\mathrm{B}$, pretreatment with a selective EGFR inhibitor AG1478 blocked ET-1induced COX-2 protein and mRNA expression in a concentration-dependent manner. Furthermore, to demonstrate whether ET-1 stimulates EGFR phosphorylation, bEnd. 3 cells were stimulated with ET-1 for the indicated time intervals. The data showed that ET-1 stimulated EGFR phosphorylation in a time-dependent manner with a maximal response within 30-60 s
(Figure 2C). Pretreatment with AG1478 (10 $\mu \mathrm{M})$ inhibited ET-1-stimulated EGFR phosphorylation during the period of observation. To confirm that EGFR is essential for ET1-induced COX-2 expression, as shown in Figure 2D, transfection with EGFR shRNA downregulated the total EGFR protein and attenuated ET-1-induced COX-2 expression. The results suggested that transactivation of RTK (EGFR) is involved in ET-1-induced COX-2 expression in bEnd. 3 cells.

\section{Involvement of PI3K/Akt cascade in ET-1-induced COX-2 expression}

Akt has been shown to be a downstream component of the EGFR pathway. Thus, we examined whether the 


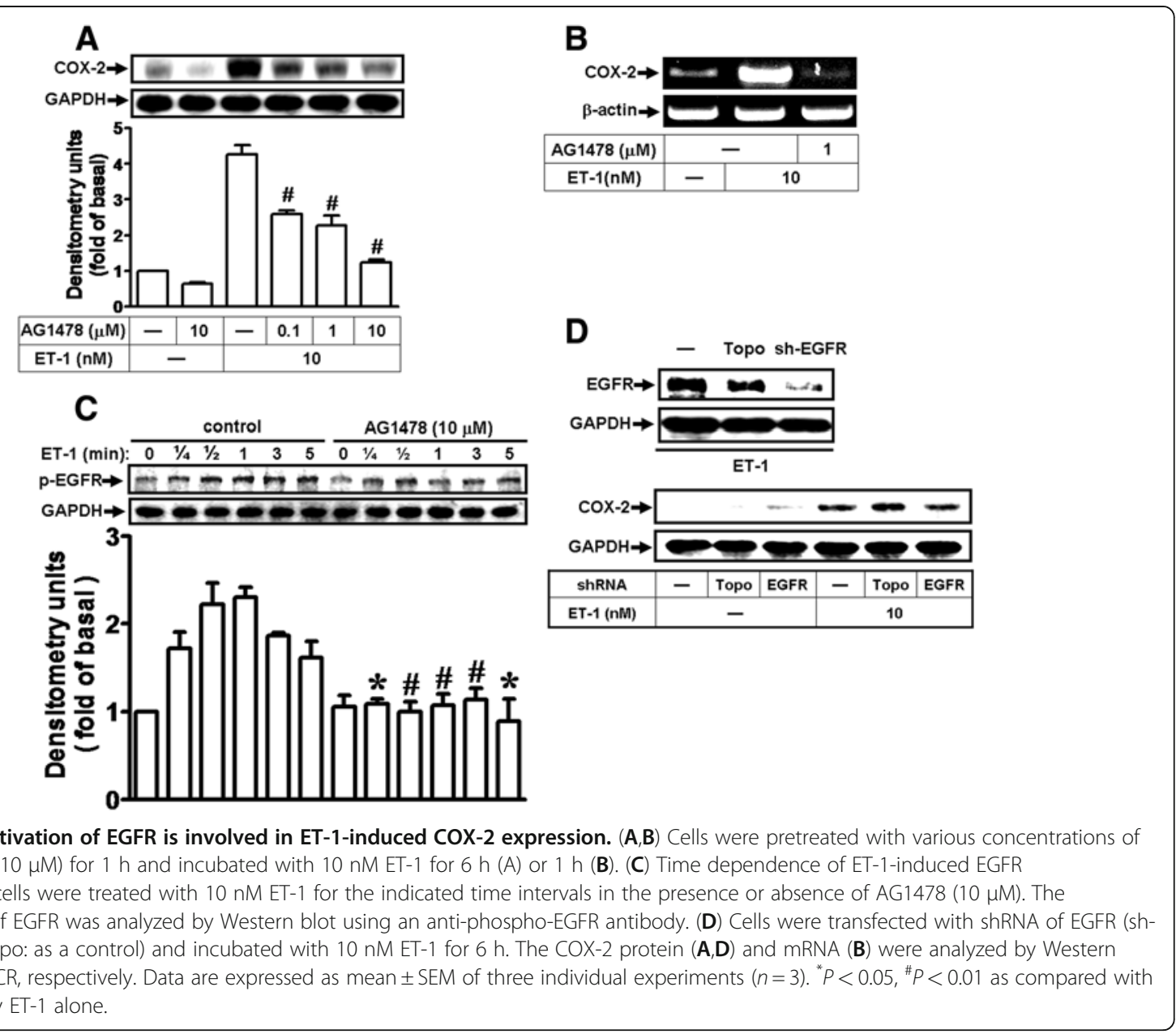

PI3K/Akt cascade is involved in ET-1-induced responses; the inhibitors of PI3K (LY294002) and Akt (SH-5) [40] were used. As shown in Figure 3A and B, pretreatment of cells with LY294002 or SH-5 concentration-dependently attenuated COX-2 protein and mRNA induction by ET-1, implying the involvement of the PI3K/Akt cascade in ET-1-induced COX-2 expression. Next, to ensure whether ET-1 stimulates PI3K/Akt cascade activation, cells were stimulated with ET-1 for the indicated time intervals, and the activation of Akt was determined by Western blotting using an anti-phospho-Akt antibody. The data showed that ET-1 stimulated Akt phosphorylation in a time-dependent manner with a maximal response within 5-10 min (Figure 3C). Pretreatment with an Akt inhibitor SH-5 (10 nM) markedly attenuated ET-1-stimulated Akt phosphorylation during the period of observation. To further confirm the role of the PI3K/Akt cascade in ET-1-induced COX-2 expression, as shown in Figure 3D, transfection with p85 or Akt shRNA blocked the total level of p85 or Akt protein and attenuated ET1 -induced COX-2 expression. The results indicated that the PI3K/Akt cascade plays a critical role in ET-1induced COX-2 expression in bEnd. 3 cells.

The c-Jun/AP-1 is required for ET-1-induced COX-2 expression and $\mathrm{PGE}_{2}$ release

It is well known that the COX-2 promoter consists of AP-1 binding sites [33]. Therefore, we determined whether the transcription factor AP-1 is involved in ET1-induced COX-2 expression in bEnd. 3 cells; an AP-1 inhibitor tanshinone IIA (TSIIA) was used. The data showed that pretreatment with TSIIA significantly inhibited ET-1-induced COX-2 protein and mRNA expression in a concentration-dependent manner (Figure 4A and B). AP-1 consists of homodimers of the Jun family or heterodimers of Jun and Fos family proteins [41]. Here we further investigated whether ET-1 stimulates AP-1 activation through regulating phosphorylation of c-Jun/AP-1; as shown in Figure 4C, ET-1 stimulated a time-dependent phosphorylation of c-Jun with a maximal response within 15-30 min in bEnd. 3 cells, which was attenuated by pretreatment with TSIIA during the period of observation. Subsequently, to further 

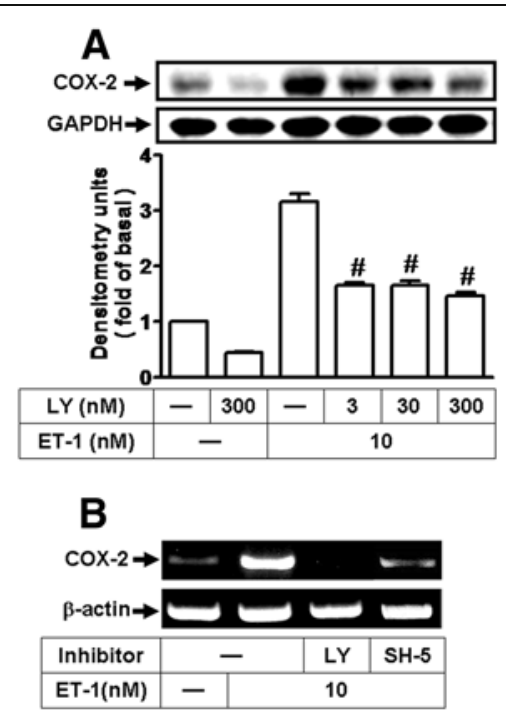

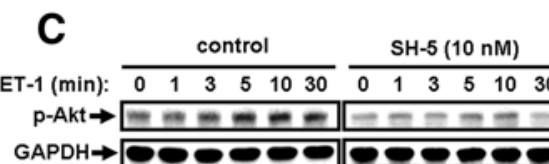
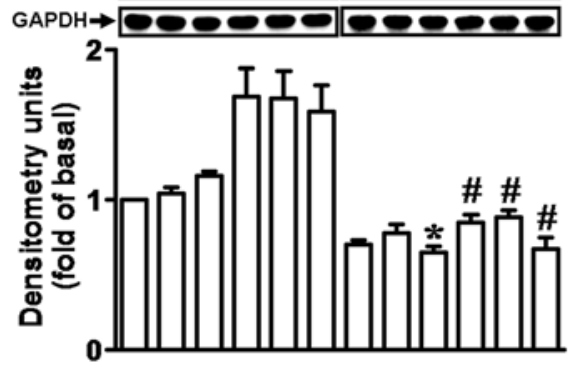

Figure 3 ET-1-induced COX-2 expression is mediated through PI3K/Akt cascade. (A,B) Cells were pretreated with various concentrations of LY294002 (3, 30, or $300 \mathrm{nM})$ or SH-5 (1, 10, or $100 \mathrm{nM})$ for $1 \mathrm{~h}$, and incubated with $10 \mathrm{nM} \mathrm{ET-1}$ for $6 \mathrm{~h}$ (A) or $1 \mathrm{~h}$ (B). (C) Time dependence of ET1-induced Akt phosphorylation; cells were treated with $10 \mathrm{nM} \mathrm{ET-1} \mathrm{for} \mathrm{the} \mathrm{indicated} \mathrm{time} \mathrm{intervals} \mathrm{in} \mathrm{the} \mathrm{presence} \mathrm{or} \mathrm{absence} \mathrm{of} \mathrm{SH-5} \mathrm{(10} \mathrm{nM).}$ The phosphorylation of Akt was analyzed by Western blot using an anti-phospho-Akt antibody. (D) Cells were transfected with p85 (sh-p85) or Akt (sh-Akt) shRNA for $24 \mathrm{~h}$ (Topo: as a control) and incubated with $10 \mathrm{nM} \mathrm{ET-1} \mathrm{for} 6 \mathrm{~h}$. The COX-2 protein (A,D) and mRNA (B) were analyzed by Western blotting and RT-PCR, respectively. Data are expressed as mean \pm SEM of three individual experiments $(n=3) .{ }^{*} P<0.05,{ }^{\#} P<0.01$ as compared with cells stimulated by ET-1 alone.

demonstrate that c-Jun is involved in the response, indeed, a siRNA of c-Jun was used. The data showed that transfection of cells with c-Jun siRNA downregulated the c-Jun protein expression and markedly attenuated ET-1-induced COX-2 expression (Figure 4D). We further determined whether c-Jun/AP-1 is also involved in ET-1-induced $\mathrm{PGE}_{2}$ release; as shown in Figure 4E, pretreatment with TSIIA or transfection with c-Jun siRNA significantly attenuated $\mathrm{PGE}_{2}$ release induced by ET-1, suggesting that c-Jun/AP-1 participates in ET-1-induced COX-2 expression and $\mathrm{PGE}_{2}$ release in bEnd. 3 cells.

\section{ET-1 stimulates c-Src-dependent transactivation of EGFR/} PI3K/Akt leading to MAPKs and c-Jun phosphorylation We have demonstrated that ET-1-induced COX-2 expression is mediated through activation of $\mathrm{c}-\mathrm{Src}$, EGFR, PI3K/Akt, or c-Jun/AP-1. Thus, we made an attempt to
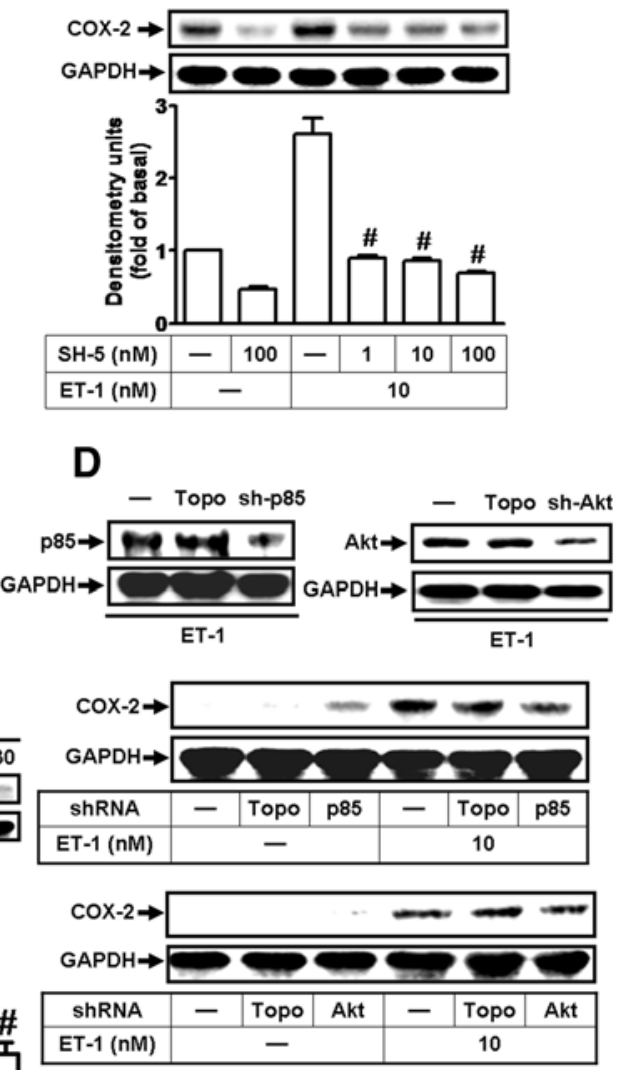

sequentially differentiate the signaling pathway of these molecules. First, cells were pretreated with antagonists of $\mathrm{ET}_{\mathrm{B}}$ receptor (BQ788) or G proteins (e.g., GPAnt2 for $G_{i}$ or $G_{s}$ protein and GPAnt2A for $G_{q}$ protein) [42] for 1 $\mathrm{h}$ prior exposure to ET-1 for the indicated time intervals. As shown in Figure 5A, ET-1-stimulated c-Src phosphorylation was significantly attenuated by pretreatment with BQ788 $(1 \mu \mathrm{M})$, GPAnt2 $(1 \mu \mathrm{M})$, and GPAnt2A $(1 \mu \mathrm{M})$, but not AG1478 and LY294002, suggesting that phosphorylation of c-Src by ET-1 was mediated through a $G_{i}$ and $G_{q}$ protein-coupled $E_{B}$ receptor. Next, pretreatment with BQ788, GPAnt2, GPAnt2A, or PP1 $(100 \mathrm{nM})$ all markedly inhibited ET-1-stimulated EGFR phosphorylation at tyrosine $845\left(\mathrm{Tyr}^{845}\right)$ residue, which was one of the phosphorylation sites by c-Src kinases during the observation period (Figure 5B). These results suggested that ET-1-transactivated EGFR may be 

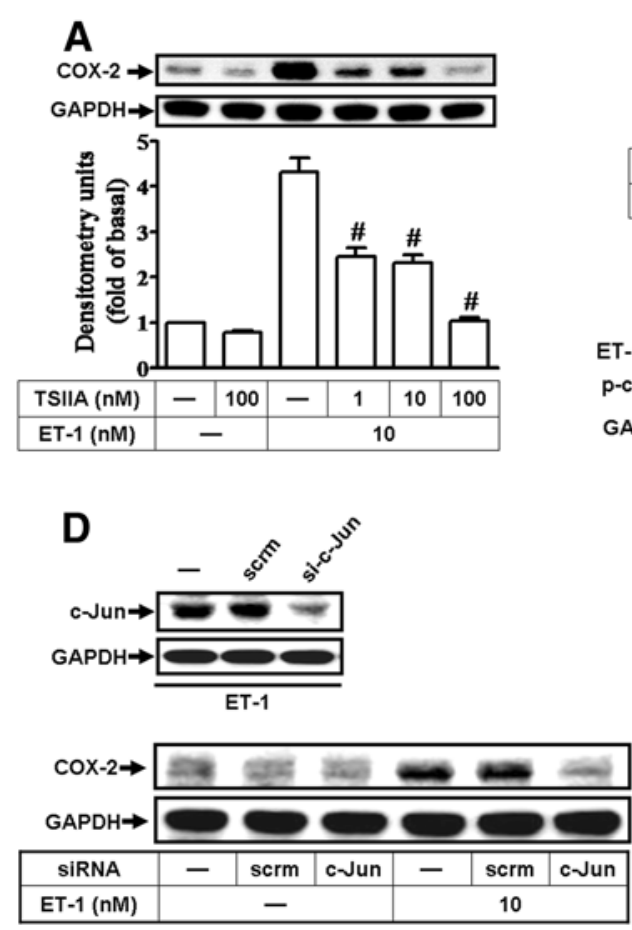

B

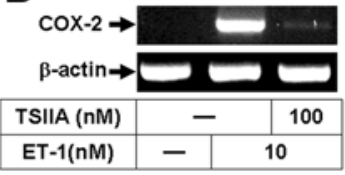

C

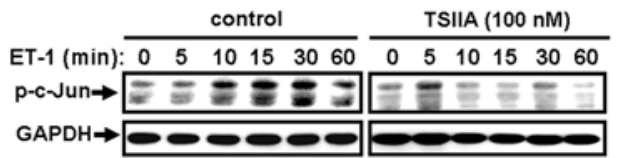

$\mathbf{E}$

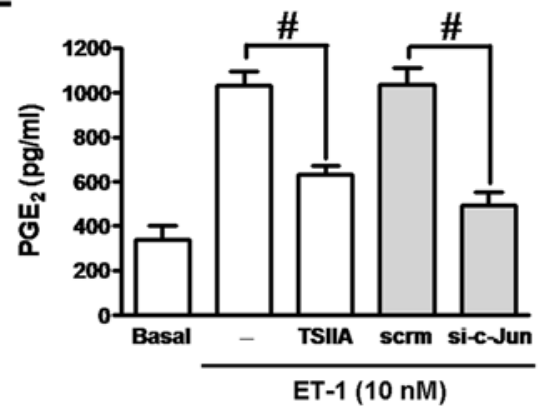

Figure 4 AP-1/c-Jun is essential for ET-1-induced COX-2 expression. $(\mathbf{A}, \mathbf{B})$ Cells were pretreated with various concentrations of tanshinone IIA (TSIIA, 1, 10, or $100 \mathrm{nM}$ ) for $1 \mathrm{~h}$ and incubated with $10 \mathrm{nM} \mathrm{ET-1}$ for $6 \mathrm{~h} \mathrm{(A)} \mathrm{or} 1 \mathrm{~h}$ (B). (C) Time dependence of ET-1-induced c-Jun/AP-1 phosphorylation; cells were treated with $10 \mathrm{nM}$ ET-1 for the indicated time intervals in the presence or absence of TSIIA (100 nM). The phosphorylation of c-Jun/AP-1 was analyzed by Western blot using an anti-phospho-c-Jun antibody. (D) Cells were transfected with siRNA of cJun (si-c-Jun) or scrambled (scrm; as a control) for $24 \mathrm{~h}$ and incubated with $10 \mathrm{nM}$ ET-1 for $6 \mathrm{~h}$. The COX-2 protein (A,D) and mRNA (B) were analyzed by Western blotting and RT-PCR, respectively. (E) Involvement of C-Jun/AP-1 in PGE 2 release induced by ET-1; cells were pretreated with TSIIA (100 nM) or transfected with c-Jun siRNA (si-c-Jun) and then incubated with ET-1 (10 nM) for $6 \mathrm{~h}$. The conditioned media were collected to assay PGE $E_{2}$ level by EIA kit. Data are expressed as mean \pm SEM of three individual experiments $(n=3) .{ }^{\#} P<0.01$ as compared with cells stimulated by ET-1 alone.

mediated through a $G_{i}$ and $G_{q}$ protein-coupled $E_{B}$ receptor linking to c-Src-dependent cascade. Furthermore, we demonstrated whether the EGFR downstream signaling molecule Akt could be activated by the same pathway; cells were pretreated with BQ788, GPAnt2, GPAnt2A, PP1, AG1478 $(1 \mu \mathrm{M})$, or LY294002 (300 nM) for $1 \mathrm{~h}$ and then stimulated with ET-1 for the indicated time intervals. As shown in Figure 5C, ET-1-stimulated Akt phosphorylation was attenuated by pretreatment with these pharmacological inhibitors, suggesting that phosphorylation of Akt by ET-1 was mediated via c-Srcdependent transactivation of EGFR. Furthermore, our previous reports have demonstrated that thrombin or BK stimulates activation of MAPKs via a c-Srcdependent EGFR transactivation in vascular smooth muscle cells $[4,31]$. Thus, to further determine whether ET-1 stimulates activation of MAPKs via c-Srcdependent EGFR transactivation, cells were pretreated with PP1, AG1478, or LY294002 before exposure to ET1 for the indicated time intervals. As expected, we found that ET-1 stimulated phosphorylation of MAPKs, including ERK1/2, p38 MAPK, and JNK1/2, in a timedependent manner (Figure 5D). Moreover, pretreatment with PP1, AG1478, or LY294002 significantly attenuated ET-1-stimulated phosphorylation of ERK1/2, p38 MAPK, and JNK1/2 (Figure 5D), suggesting that ET-1 stimulates MAPKs phosphorylation via a c-Srcdependent EGFR/PI3K/Akt cascade. Pretreatment with the inhibitor of ERK (U0126, $1 \mu \mathrm{M})$, p38 MAPK (SB202190, $300 \mathrm{nM}$ ), or JNK (SP600125, $300 \mathrm{nM}$ ) markedly attenuated ET-1-induced COX-2 expression (Figure 5D, lower panel), suggesting that ET-1-induced COX-2 expression is mediated through these MAPKs. We further demonstrated whether activation of c-Jun/ AP-1 by ET-1 was also mediated through c-Srcdependent transactivation of EGFR/PI3K/Akt and MAPKs in b.End.3 cells. As shown in Figure 5E, pretreatment with these inhibitors as described above markedly attenuated ET-1-stimulated phosphorylation of c-Jun during the period of observation, suggesting that ET-1 stimulated c-Jun phosphorylation via the same pathway. These results indicated that ET-1-induced 


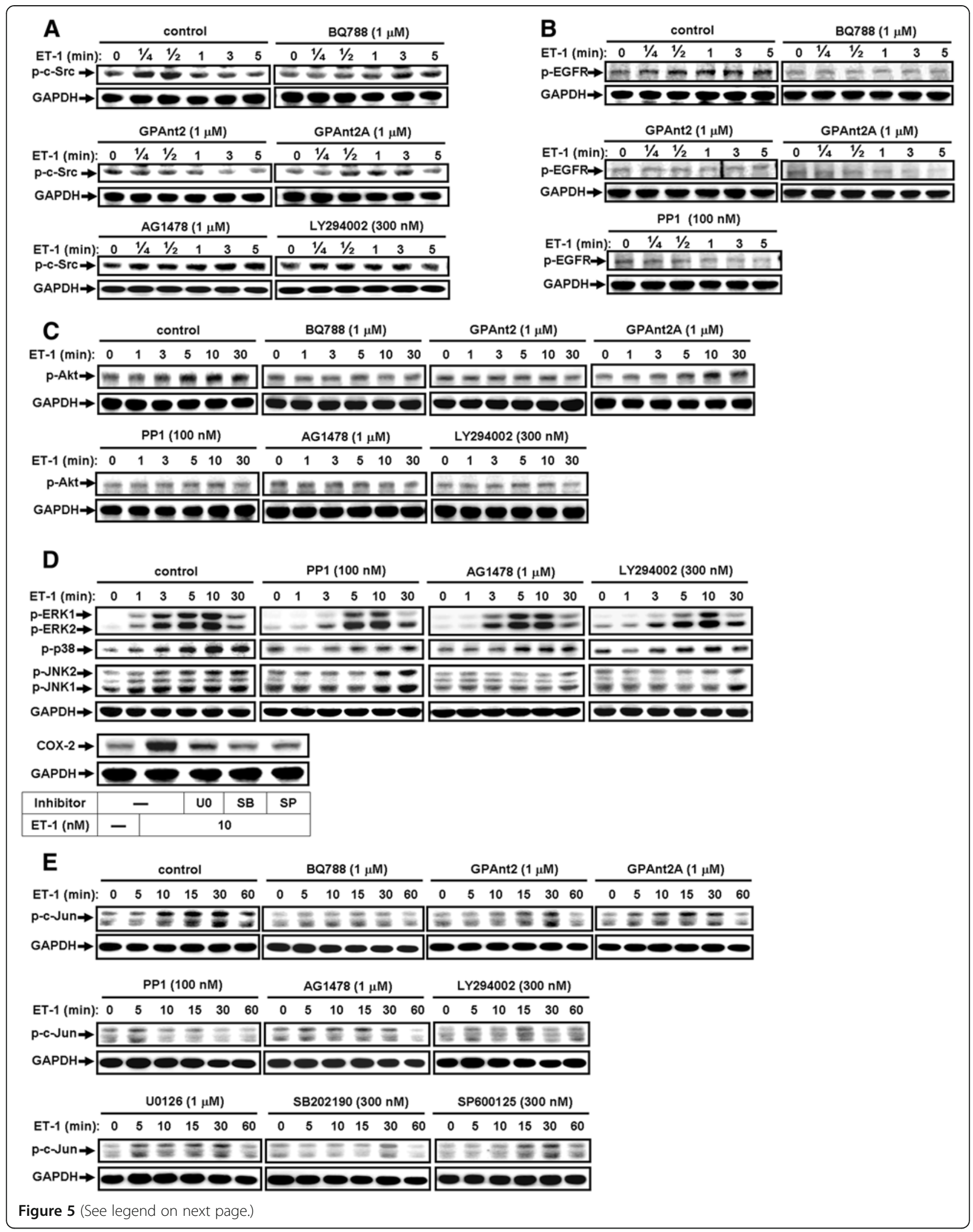


(See figure on previous page.)

Figure 5 ET-1 stimulates c-Src-dependent transactivation of EGFR/PI3K/Akt leading to MAPKs and c-Jun phosphorylation. (A) For c-Src phosphorylation, cells were incubated with $10 \mathrm{nM} \mathrm{ET-1}$ for the indicated time intervals in the absence or presence of BQ788 (1 $\mu \mathrm{M})$, GPAnt2 (1

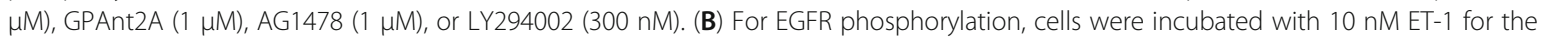
indicated time intervals in the absence or presence of BQ788, GPAnt2, GPAnt2A, or PP1 (100 nM). (C) For Akt phosphorylation, cells were incubated with $10 \mathrm{nM}$ ET-1 for the indicated time intervals in the absence or presence of BQ788, GPAnt2, GPAnt2A, PP1, AG1478, or LY294002. (D) For MAPKs phosphorylation, cells were incubated with $10 \mathrm{nM}$ ET-1 for the indicated time intervals in the absence or presence of PP1, AG1478, or LY294002. For COX-2 expression, cells were incubated with ET-1 (10 nM) for $6 \mathrm{~h}$ in the absence or presence of U0126 (1 $\mu$ M), SB202190 (300 nM), or SP600125 (300 nM). (E) For c-Jun phosphorylation, cells were incubated with $10 \mathrm{nM}$ ET-1 for the indicated time intervals in the absence or presence of BQ788, GPAnt2, GPAnt2A, PP1, AG1478, LY294002, U0126 (1 MM), SB202190 (300 nM), or SP600125 (300 nM). The cell lysates were collected and analyzed by Western blotting using an anti-phospho-c-Src, anti-phospho-EGFR, anti-phospho-Akt, anti-phospho-ERK1/2, antiphospho-p38 MAPK, anti-phospho-JNK1/2, anti-phospho-c-Jun, or anti-GAPDH (as an internal control) antibody. The figure represents one of three similar experiments $(n=3)$.

MAPKs-dependent c-Jun phosphorylation was mediated through c-Src-dependent transactivation of EGFR/PI3K/ Akt in bEnd. 3 cells.

\section{ET-1 stimulates AP-1 activation and recruitment of AP-1 to COX-2 gene promoter via c-Src-dependent EGFR/PI3K/ Akt/MAPKs pathway}

To investigate whether ET-1-stimulated AP-1 transcription activity is also mediated through this c-Srcdependent pathway, the AP-1 promoter reporter construct was used. As shown in Figure 6A, ET-1 (10 nM) stimulated an AP-1-luciferase activity increase in a timedependent manner with a maximal response within 90 min, which was attenuated by pretreatment with TSIIA $(100 \mathrm{nM})$ [43]. Furthermore, pretreatment with PP1, AG1478, LY294002, SH-5, U0126, SB202190, or SP600125 also attenuated ET-1-stimulated AP-1 transcriptional activity (Figure 6B). It has been shown that the COX-2 promoter region contains AP-1 binding sites. Hence, we used a ChIP-PCR assay to determine whether ET-1-stimulated recruitment of c-Jun/AP-1 to the COX2 promoter is involved in COX-2 gene expression. We designed a pair of primers for the COX-2 promoter $(-371$ to +70$)$ region, containing an AP-1 binding site. Chromatin was immunoprecipitated using an anti-c-Jun antibody, and the COX-2 promoter region was amplified by PCR. As shown in Figure 6C (upper part), ET-1 stimulated in vivo binding of c-Jun to the COX-2 promoter in a time-dependent manner with a maximal response within $90 \mathrm{~min}$, which was attenuated by pretreatment with TSIIA, U0126, SB202190, SP600125, or BQ788 (Figure 6C, lower part).

We next examined whether ET-1-induced COX-2 promoter activity is also regulated by these signaling pathways. ET-1-stimulated increase in COX-2 promoter activity was attenuated by pretreatment with PP1, AG1478, LY294002, SH-5, U0126, SB202190, SP600125, or TSIIA (Figure 6D), suggesting that ET-1-induced COX-2 promoter activity is mediated through c-Srcdependent EGFR/PI3K/Akt/MAPKs and c-Jun/AP-1 in bEnd. 3 cells. To further ensure that AP-1 is involved in
ET-1-induced COX-2 promoter activity via binding to the AP-1 binding element on the COX-2 promoter region, the wild-type COX-2 promoter mutated by singlepoint mutation of the AP-1 binding site (mu-AP-1) was constructed (as illustrated in Figure 6E, upper part). ET1-stimulated COX-2 promoter activity was significantly blocked in cells transfected with an mt-AP1-COX-2 reporter construct (Figure 6E, lower part). These results confirmed that ET-1-induced COX-2 promoter activity is mediated through binding of AP-1 (c-Jun) to the AP-1 element of the COX-2 promoter region.

\section{ET-1-induced $\mathrm{PGE}_{2}$ release is mediated through c-Src- dependent transactivation of EGFR}

Ultimately, to demonstrate the functional activity of upregulated COX-2 by ET- 1 on bEnd. 3 cells, we evaluated the $\mathrm{PGE}_{2}$ release by EIA kit assay. The levels of $\mathrm{PGE}_{2}$ release were measured at $6 \mathrm{~h}$ induced by ET-1 $(10 \mathrm{nM})$. ET-1-induced $\mathrm{PGE}_{2}$ release was significantly blocked by pretreatment with genistein (Gen, $1 \mu \mathrm{M})$, PP1 (10 nM), AG1478 (AG, $10 \mu \mathrm{M})$, LY294002 (LY, 300 $\mathrm{nM}), \mathrm{SH}-5(10 \mu \mathrm{M})$, U0126 (U0, $1 \mu \mathrm{M})$, SB202190 (SB, $300 \mathrm{nM}$ ), or SP600125 (SP, $300 \mathrm{nM}$ ) (Figure 7A), suggesting that upregulation of COX-2 is mediated through c-Src-dependent transactivation of EGFR/PI3K/Akt/ MAPKs pathway associated with $\mathrm{PGE}_{2}$ released by ET-1 in bEnd. 3 cells.

\section{Discussion}

ET-1 is elevated in the regions of vascular injuries and inflammation $[9,19,44]$. Circumstantial evidence has further demonstrated that overexpression of ET-1 on endothelial cells has deleterious effects on ischemic brain $[7,10,11]$. Additionally, ET-1 has been shown to upregulate the expression of COX-2 through MAPKs in various cell types $[25,26,45]$. The upregulation of COX-2 has been shown in several inflammatory diseases and displays a wide range of biological activities in different tissues, blood vessels in particular, including development, proliferation, cancers, and inflammation [1,2]. Several studies have also demonstrated that high levels of PGs, 


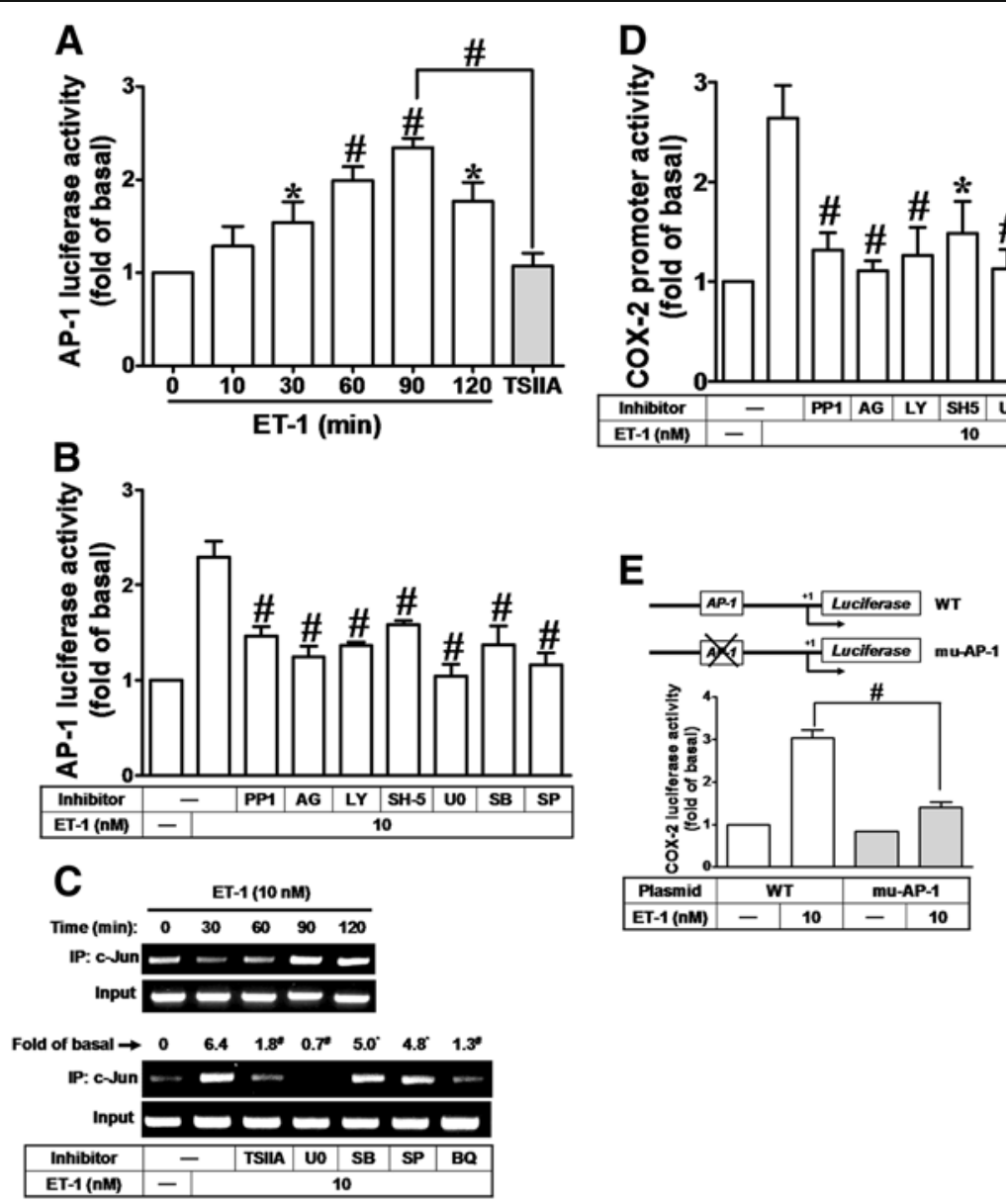

Figure 6 ET-1-stimulated COX-2 promoter activity is mediated through AP-1-dependent pathway. (A) Time dependence of ET-1-enhanced AP-1 transcription activity; cells were transfected with an AP-1-luciferase reporter gene and then exposed to ET-1 for the indicated time intervals. (B) After transfection with AP-1-luciferase reporter gene, the cells were pretreated with PP1 PP1 (100 nM), AG1478 (AG, 1 HM), LY294002 (LY, 300 nM), SH-5 (10 nM), U0126 (U0, 1 MM), SB202190 (SB, 300 nM), SP600125 (SP, 300 nM), or (A) TSIIA (100 nM) for 1 h and then incubated with ET-1 (10 nM) for 90 min. (C) Cells were pretreated without or with TSIIA, U0126 (U0), SB202190 (SB), SP600125 (SP), or BQ788 (BQ) for $1 \mathrm{~h}$ and then incubated with ET-1 (10 nM) for the indicated time intervals (upper panel) or $90 \mathrm{~min}$ (lower panel). The c-Jun/AP-1 binding activity was analyzed by chromatin-IP (ChIP)-PCR assay. (D) For COX-2 promoter activity, cells were pretreated with PP1, AG1478 (AG), LY294002 (LY), SH-5, U0126 (U0), SB202190 (SB), or SP600125 (SP), or TSIIA for $1 \mathrm{~h}$ and then incubated with ET-1 (10 nM) for 6 h. (E) Schematic representation of a 5'-promoter regions of the mouse different COX-2 promoter constructs, either wild-type (WT) or mutated by single-point mutation of the AP-1 binding site (mu-AP-1) cloned to the pGL-luciferase reporter gene; the translational start site $(+1)$ of the luciferase reporter gene is indicated by an arrow. Cells were transfected with WT COX-2 promoter reporter gene (WT) or AP-1 mutated COX-2 promoter reporter gene (mu-AP-1) and then incubated with or without ET-1 (10 nM) for $6 \mathrm{~h}$. The promoter reporter activity was determined. Data are expressed as mean \pm SEM of at least three individual experiments $(n=3) .{ }^{*} P<0.05,{ }^{\#} P<0.01$ as compared with ET-1 alone.

synthesized by inducible COX-2, are involved in inflammatory responses. However, the mechanisms of ET-1induced COX-2 expression in brain endothelial cells remain unclear. Herein we used cultured models of mouse brain endothelial cell line (bEnd.3) and applied Western blot analysis, selective pharmacological inhibitors, transfection with shRNA or siRNAs, ChIP-PCR, and promoter reporter assay to investigate the signaling pathways underlying ET-1-induced COX-2 expression and $\mathrm{PGE}_{2}$ release. Our results demonstrated that in bEnd. 3 cells activation of $\mathrm{ET}_{\mathrm{B}}$ receptor-mediated c-Src- dependent transactivation of EGFR, PI3K/Akt, MAPKs (ERK, p38 MAPK, and JNK), and the AP-1 signaling cascade is essential for ET-1-induced COX-2 gene expression and $\mathrm{PGE}_{2}$ release.

Several studies have found that an agonist of GPCR coupling to different $G$ proteins transactivates RTKs such as EGFR in diverse cell types and sequential linking to activation of downstream signals such as MAPKs $[19,21,22]$. We have demonstrated a significant expression of $\mathrm{ET}_{\mathrm{B}}$ receptor in bEnd.3 cells by RT-PCR. Hence, in this study, the involvement of $\mathrm{ET}_{\mathrm{B}}$ receptors in these 


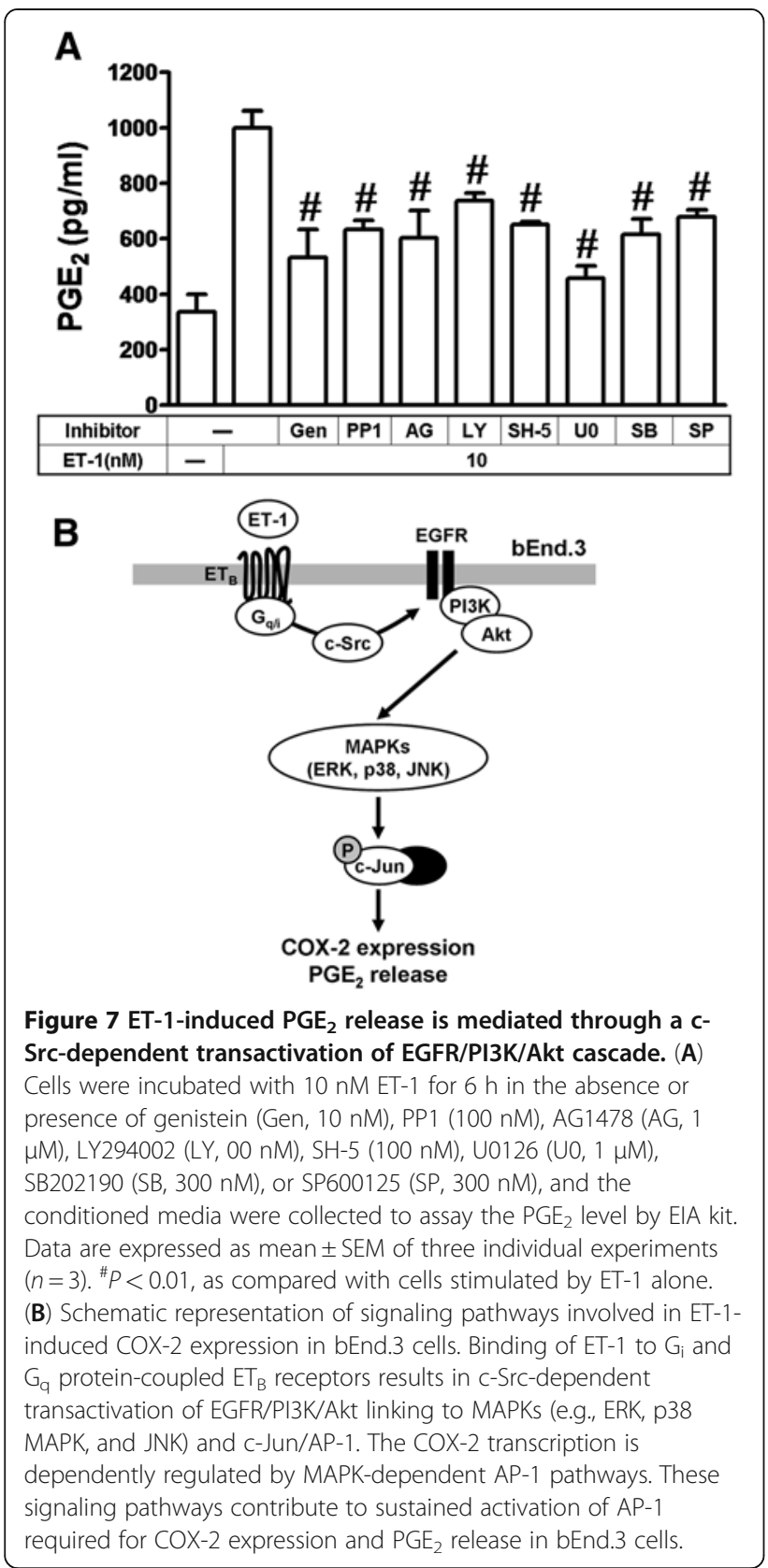

responses was confirmed because pretreatment with BQ-788 (an $\mathrm{ET}_{\mathrm{B}}$ receptor antagonist) reduced the ET-1stimulated phosphorylation of c-Src, EGFR, Akt, MAPKs (i.e., ERK, p38 MAPK, JNK), and c-Jun/AP-1 (Figure 5), but not by an $\mathrm{ET}_{\mathrm{A}}$ receptor antagonist $\mathrm{BQ}-123$ (data not shown), suggesting that the $\mathrm{ET}_{\mathrm{B}}$ receptor predominantly mediates ET-1 stimulation in these responses in bEnd.3 cells. Next, several subtypes of $\mathrm{G}$ proteins are potentially implicated in ET-1-induced COX-2 expression. We used GPA2 (a $\mathrm{G}_{\mathrm{i} / \mathrm{o}}$ protein antagonist) and GPA2A (a $\mathrm{G}_{\mathrm{q}}$ protein antagonist) to interrupt $G$ protein signaling and the consequent phosphorylation of these signaling molecules
(Figure 5), indicating that ET-1-stimulated c-Srcdependent transactivation of EGFR is mediated by a GPCR (i.e., $E_{B}$ ) coupling to either $G_{i}$ or $G_{q}$ protein in bEnd.3 cells, consistent with previous studies from esophageal smooth muscle cells [45] and rat brain astrocytes [20]. In contrast, a report shows that ET-1 induced COX-2 expression via $\mathrm{ET}_{\mathrm{A}}$ receptors in peripheral lung microvascular smooth muscle cells [25]. However, in respiratory and cardiovascular systems, both ET receptor subtypes, $\mathrm{ET}_{\mathrm{A}}$ especially, are involved in progression of airway [46] and cardiovascular diseases [44]. These differences may be due to cell-type-specific or different experimental conditions.

It has been reported that transactivation of RTK, EGFR especially, occurs in response to activation of many GPCRs such as endothelin-1 [27,32,39]. Several lines of evidence have also shown that the $\beta \gamma$ complex of $\mathrm{G}_{\text {i }}$ protein activates non-RTKs, such as the c-Src family, which might transactivate RTKs and modulate various cellular functions [47,48]. Moreover, the involvement of c-Src in the transactivation of EGFR by GPCRs has been reported in various cell types $[47,49]$. Although transactivation of EGFR by GPCR agonists has been well studied, the signaling mechanism by which ET-1-stimulated transactivation of RTK such as EGFR in brain microvascular endothelial cells has not been completely understood. Thus, in this study, we investigated whether protein tyrosine kinase pathways, such as c-Srcdependent transactivation of EGFR, are involved in ET-1-induced COX-2 expression. First, our data demonstrated that ET-1-induced COX-2 expression is mediated through protein tyrosine kinases including $\mathrm{c}-\mathrm{Src}$ and EGFR by pharmacological inhibitors and transfection with a c-Src or EGFR shRNA, which all significantly inhibited induction of COX-2 gene expression by ET-1 (Figures 1 and 2). Next, we found that ET-1 can stimulate phosphorylation of $c$-Src and EGFR via $G_{i}$ and $G_{q}$ protein-coupled $\mathrm{ET}_{\mathrm{B}}$ receptors (Figure $5 \mathrm{~A}$ and $\mathrm{B}$ ), and following the PP1 significantly inhibited c-Src and EGFR phosphorylation (Figures $1 \mathrm{E}$ and $5 \mathrm{~B}$ ) and subsequent upregulation of COX-2 (Figure $1 \mathrm{C}$ and $\mathrm{D}$ ) and $\mathrm{PGE}_{2}$ release (Figure 7A). These results demonstrated that c-Srcdependent EGFR transactivation plays a critical role in ET-1-induced COX-2 expression and $\mathrm{PGE}_{2}$ release, consistent with previous reports showing the involvement of EGFR transactivation in ET-1-induced cell proliferation in ovarian cancer cells [29] and thrombin- or ET-1induced COX-2 expression in VSMCs $[4,30,44]$.

Abnormal MAPK regulation might be implicated in several models of CNS injury and inflammation [50]. Several lines of evidence demonstrate that MAPKs could be activated by GPCR agonists by different signal pathways [23]. MAPKs activation by ET-1 has been shown to modulate various cellular responses in various cell types 
$[20,24]$. Thus, activation of MAPKs may be implicated in the expression of inflammatory genes in several models of vascular injury and inflammation [4,51]. Additionally, an agonist of GPCR has been found to transactivate EGFRs in diverse cell types and shows sequential linking to MAPK activation, ERK1/2 especially $[19,21,22]$. Our data showed that ET-1 stimulated c-Src-dependent transactivation of the EGFR and PI3K/Akt cascade (Figure 5A-C), and pretreatment with PP1, AG1478, or LY294002 attenuated phosphorylation of MAPKs, including ERK1/2, p38 MAPK, and JNK1/2 (Figure 5D), suggesting that ET-1-stimulated activation of MAPKs is mediated through c-Src-dependent transactivation of the EGFR and PI3K/Akt cascade. Moreover, ET-1-induced COX-2 expression was mediated through MAPKs (Figure 5D, lower panel). Although most studies indicate that activation of EGFR may lead to ERK1/2 activation via a Grb2/Sos/Ras/Raf cascade, increasing evidence demonstrates that transactivation of the EGFR/PI3K/Akt cascade also plays a critical role in the activation of ERK1/2. Our results are consistent with previous reports indicating that BK mediates cell proliferation or thrombin induces COX-2 expression via transactivation of the EGFR and ERK1/2 cascade in VSMCs [4,31], and thrombin stimulates cell migration in SMCs [52]. In contrast, many studies suggest that thrombin-induced mitogenic action in astrocytes or VSMCs occurs independently of EGFR transactivation [53,54]. Regarding the MAPKs, our results are the first to show that p38 MAPK and JNK $1 / 2$ play a critical role in the induction of COX-2 by ET-1 in brain microvascular endothelial cells.

It has been well established that inflammatory responses following exposure to extracellular stimuli are highly dependent on activation of AP-1 transcription factor, which plays an important role in the regulation of several gene expressions [41]. The 5 '-flanking region of the COX-2 promoter has been shown to contain several binding sequences for various transcription factors including AP-1 $[33,35]$. Therefore, the regulation of COX2 transcription may be mediated by aberrant activation of several distinct transcription factors dependent on agonists $[26,55]$. These studies suggest that AP-1 plays a critical role in the regulation of COX-2 expression in the development of inflammatory responses. Our data showed that ET-1-induced COX-2 gene expression and $\mathrm{PGE}_{2}$ release were significantly abolished by an AP-1 inhibitor tanshinone IIA (TSIIA) [43] (Figure 4A, B, and E) or c-Jun (a AP-1 subunit) siRNA (Figure 4D and E), suggesting that c-Jun/AP-1 is involved in ET-1-induced COX-2 expression in bEnd.3 cells. Moreover, ET-1stimulated c-Jun phosphorylation (Figure 4C) and AP-1Luc transcriptional activity (Figure 6A) were significantly inhibited by TSIIA and three MAPK inhibitors U0126 (MEK1/2), SB202190 (p38 MAPK), or SP600125 (JNK1/
2) (Figures 4C, 5E, 6A, and 6B). Here, we found the inhibitory effect of TSIIA on ET-1-stimulated c-Jun phosphorylation in bEnd.3 cells, which is consistent with our recent study in brain astrocytes [56]. Our data further showed that these ET-1-stimulated responses were significantly blocked by PP1, AG1478, and LY294002 in these cells (Figures 5E, 6B, and 6D). These findings suggested that ET-1-induced COX-2 expression and $\mathrm{PGE}_{2}$ release are mediated through an AP-1-dependent mechanism via c-Src-dependent transactivation of EGFR, PI3K/Akt, and MAPK cascades. These findings are consistent with recent studies indicating that COX-2 expression induced by phorbol ester (TPA) was mediated by JNK1/2 and AP-1 activation in human breast epithelial cell line (MCF-10A) [57] and COX-2 expression induced by EV-71 via p42/p44 MAPK linking to AP-1 activation in rat brain astrocytes [58]. The involvement of AP-1 in ET-1-induced COX-2 expression is also consistent with previous a report indicating that ET-1-stimulated activation of AP-1 regulates expression of other target genes involved in various CNS inflammatory processes [20].

\section{Conclusions}

In this study, we demonstrated that the ET-1/ET receptor system exerts its inducing effects on COX-2 gene expression and $\mathrm{PGE}_{2}$ release in mouse cultured brain endothelial (bEnd.3) cells. The $G_{i}$ and $G_{q}$ proteincoupled $\mathrm{ET}_{\mathrm{B}}$ receptor, c-Src-dependent transactivation of EGFR, PI3K/Akt, ERK1/2, p38 MAPK, JNK1/2, and c-Jun/AP-1 cascades cooperatively mediated these effects of ET-1. Based on the observations from the literature and our findings, Figure 7B depicts a model for the signaling mechanisms implicated in ET-1-induced COX-2 gene expression in mouse-cultured bEnd.3 cells. These findings concerning ET-1-induced COX-2 expression and $\mathrm{PGE}_{2}$ generation imply that ET-1 might play a critical role in brain injury, vascular inflammation, and CNS disorders, mediated by c-Src-dependent transactivation of EGFR linking to MAPKs/AP-1 pathways in brain microvascular endothelial cells. Pharmacological approaches suggest that targeting COX-2 and its upstream signaling components may provide useful therapeutic strategies for brain injury and inflammatory diseases.

\section{Competing interests}

The authors declare that they have no competing interests.

\section{Acknowledgements}

This work was supported by the National Science Council, Taiwan, grant nos.: NSC98-2321-B-182-004 and NSC99-2321-B-182-003, NSC98-2314-B-182-021-

MY3, and NSC98-2320-B-255-001-MY3; Chang Gung Medical Research Foundation, grant nos.: CMRPG391032, CMRPG381522, CMRPD170493, CMRPD180372, and CMRPF170023 and CMRPF1A0061; the Ministry of Education, Taiwan; grant nos.: EMRPD1A0831, EMRPD1B0311, EMRPD1A0841, and EMRPD1B0321. 


\section{Author details}

'Department of Nursing, Division of Basic Medical Sciences, Chang Gung University of Science and Technology, Tao-Yuan, Taiwan. ${ }^{2}$ Department of Anesthetics, Chang Gung Memorial Hospital and College of Medicine, Chang Gung University, Kwei-San, Tao-Yuan, Taiwan. ${ }^{3}$ Department of Physiology and Pharmacology, and Health Aging Research Center, College of Medicine, Chang Gung University, Tao-Yuan, Taiwan. ${ }^{4}$ School of Medicine, National Yang Ming University, Taipei, Taiwan. ${ }^{5}$ Department of Pharmacology, Chang Gung University, 259 Wen-Hwa 1st Road, Kwei-San, Tao-Yuan, Taiwan.

\section{Authors' contributions}

$\mathrm{HLH}$ and CCL designed and performed the experiments, acquisition and analysis of data, and drafted the manuscript. HJC and Caleb MY helped to perform experiments and prepare the manuscript. CMY conceived of the study, participated in its design and coordination, been involved in drafting the manuscript and revising it critically for important intellectual content, and gave final approval of the version to be published. All authors have read and approved the final version of this manuscript.

Received: 2 February 2012 Accepted: 2 July 2012

Published: 2 July 2012

\section{References}

1. Williams CS, Mann M, DuBois RN: The role of cyclooxygenases in inflammation, cancer, and development. Oncogene 1999, 18:7908-7916.

2. Smith WL, DeWitt DL, Garavito RM: Cyclooxygenases: structural, cellular, and molecular biology. Annu Rev Biochem 2000, 69:145-182.

3. Syeda F, Grosjean J, Houliston RA, Keogh RJ, Carter TD, Paleolog E, WheelerJones CP: Cyclooxygenase-2 induction and prostacyclin release by protease-activated receptors in endothelial cells require cooperation between mitogen-activated protein kinase and NF-KB pathways. J Biol Chem 2006, 281:11792-11804.

4. Hsieh HL, Sun CC, Wang TS, Yang CM: PKC- $\delta / c-S r c-m e d i a t e d ~ E G F$ receptor transactivation regulates thrombin-induced $\mathrm{COX}-2$ expression and $\mathrm{PGE}_{2}$ production in rat vascular smooth muscle cells. Biochim Biophys Acta 2008, 1783:1563-1575.

5. Ejima K, Layne MD, Carvajal IM, Kritek PA, Baron RM, Chen YH, Vom Saal J, Levy BD, Yet SF, Perrella MA: Cyclooxygenase-2-deficient mice are resistant to endotoxin-induced inflammation and death. FASEB J 2003 17:1325-1327.

6. Minghetti L: Cyclooxygenase-2 (COX-2) in inflammatory and degenerative brain diseases. J Neuropathol Exp Neurol 2004, 63:901-910.

7. McCarron RM, Chen Y, Tomori T, Strasser A, Mechoulam R, Shohami E, Spatz M: Endothelial-mediated regulation of cerebral microcirculation. J Physiol Pharmacol 2006, 57:133-144.

8. Lerman A, Zeiher AM: Endothelial function: cardiac events. Circulation 2005, 111:363-368

9. Böhm F, Pernow J: The importance of endothelin-1 for vascular dysfunction in cardiovascular disease. Cardiovasc Res 2007, 76:8-18.

10. Levin ER: Endothelins. N Engl J Med 1995, 333:356-363.

11. Kawanabe Y, Nauli SM: Endothelin. Cell Mol Life Sci 2011, 68:195-203.

12. Rubanyi GM, Polokoff MA: Endothelins: molecular biology, biochemistry, pharmacology, physiology, and pathophysiology. Pharmacol Rev 1994, 46:325-415.

13. Chen P, Shibata M, Zidovetzki R, Fisher M, Zlokovic BV, Hofman FM: Endothelin-1 and monocyte chemoattractant protein-1 modulation in ischemia and human brain-derived endothelial cell cultures. $J$ Neuroimmunol 2001, 116:62-73.

14. Hasselblatt M, Lewczuk P, Löffler BM, Kamrowski-Kruck H, von Ahsen N, Sirén $\mathrm{AL}$, Ehrenreich $\mathrm{H}$ : Role of the astrocytic $\mathrm{ET}(\mathrm{B})$ receptor in the regulation of extracellular endothelin-1 during hypoxia. Glia 2001, 34:18-26.

15. ladecola C: Neurovascular regulation in the normal brain and in Alzheimer's disease. Nat Rev Neurosci 2004, 5:347-360.

16. Guo S, Lo EH: Dysfunctional cell-cell signaling in the neurovascular unit as a paradigm for central nervous system disease. Stroke 2009, 40:54-S7.

17. Zidovetzki R, Chen P, Chen M, Hofman FM: Endothelin-1-induced interleukin-8 production in human brain-derived endothelial cells is mediated by the protein kinase $C$ and protein tyrosine kinase pathways. Blood 1999, 94:1291-1299.
18. Arai H, Hori S, Aramori I, Ohkubo H, Nakanishi S: Cloning and expression of a cDNA encoding an endothelin receptor. Nature 1990, 348:730-732.

19. Bouallegue A, Daou GB, Srivastava AK: Endothelin-1-induced signaling pathways in vascular smooth muscle cells. Curr Vasc Pharmacol 2007, 5:45-52.

20. Wang $H H$, Hsieh $H L$, Wu CY, Yang CM: Endothelin-1 enhances cell migration via matrix metalloproteinase-9 up-regulation in brain astrocytes. J Neurochem 2010, 113:1133-1149.

21. Simonson MS, Herman WH: Protein kinase $\mathrm{C}$ and protein tyrosine kinase activity contribute to mitogenic signaling by endothelin-1. Cross-talk between G protein-coupled receptors and pp60c-src. J Biol Chem 1993, 268:9347-9357.

22. Aramori I, Nakanishi S: Coupling of two endothelin receptor subtypes to differing signal transduction in transfected Chinese hamster ovary cells. J Biol Chem 1992, 267:12468-12474.

23. Marshall CJ: MAP kinase kinase kinase, MAP kinase kinase and MAP kinase. Curr Opin Genet Dev 1994, 4:82-89.

24. Marasciulo FL, Montagnani M, Potenza MA: Endothelin-1: the yin and yang on vascular function. Curr Med Chem 2006, 13:1655-1665.

25. Chen D, Balyakina EV, Lawrence M, Christman BW, Meyrick B: Cyclooxygenase is regulated by ET-1 and MAPKs in peripheral lung microvascular smooth muscle cells. Am J Physiol Lung Cell Mol Physiol 2003, 284:L614-L621.

26. Pratt PF, Bokemeyer D, Foschi M, Sorokin A, Dunn MJ: Alterations in subcellular localization of p38 MAPK potentiates endothelin-stimulated COX-2 expression in glomerular mesangial cells. J Biol Chem 2003, 278:51928-51936.

27. Zwick E, Hackel PO, Prenzel N, Ullrich A: The EGF receptor as central transducer of heterologous signalling systems. Trends Pharmacol Sci 1999, 20:408-412.

28. Prenzel N, Zwick E, Daub H, Leserer M, Abraham R, Wallasch C, Ullrich A: EGF receptor transactivation by $\mathrm{G}$-protein-coupled receptors requires metalloproteinase cleavage of proHB-EGF. Nature 1999, 402:884-888

29. Spinella F, Rosanò L, Elia G, Di Castro V, Natali PG, Bagnato A: Endothelin-1 stimulates cyclooxygenase-2 expression in ovarian cancer cells through multiple signaling pathways: evidence for involvement of transactivation of the epidermal growth factor receptor. J Cardiovasc Pharmacol 2004, 44(Suppl 1):S140-S143.

30. Li Y, Lévesque LO, Anand-Srivastava MB: Epidermal growth factor receptor transactivation by endogenous vasoactive peptides contributes to hyperproliferation of vascular smooth muscle cells of SHR. Am J Physiol Heart Circ Physiol 2010, 299:H1959-H1967.

31. Yang CM, Lin Ml, Hsieh HL, Sun CC, Ma YH, Hsiao LD: Bradykinin-induced p42/p44 MAPK phosphorylation and cell proliferation via Src, EGF receptors, and PI3-K/Akt in vascular smooth muscle cells. J Cell Physiol 2005, 203:538-546

32. Chen $\mathrm{CH}$, Cheng $\mathrm{TH}$, Lin $\mathrm{H}$, Shih NL, Chen YL, Chen YS, Cheng CF, Lian WS, Meng TC, Chiu WT, Chen JJ: Reactive oxygen species generation is involved in epidermal growth factor receptor transactivation through the transient oxidization of Src homology 2-containing tyrosine phosphatase in endothelin-1 signaling pathway in rat cardiac fibroblasts. Mol Pharmacol 2006, 69:1347-1355.

33. Tanabe T, Tohnai N: Cyclooxygenase isozymes and their gene structures and expression. Prostaglandins Other Lipid Mediat 2002, 68-69:95-114

34. Chun KS, Kim SH, Song YS, Surh YJ: Celecoxib inhibits phorbol esterinduced expression of COX-2 and activation of AP-1 and p38 MAP kinase in mouse skin. Carcinogenesis 2004, 25:713-722.

35. Kundu JK, Shin YK, Surh YJ: Resveratrol modulates phorbol ester-induced pro-inflammatory signal transduction pathways in mouse skin in vivo: NF-KB and AP-1 as prime targets. Biochem Pharmacol 2006, 72:1506-1515.

36. Hunot S, Vila M, Teismann P, Davis RJ, Hirsch EC, Przedborski S, Rakic P, Flavell RA: JNK-mediated induction of cyclooxygenase 2 is required for neurodegeneration in a mouse model of Parkinson's disease. Proc Natl Acad Sci USA 2004, 101:665-670.

37. Yang F, Bleich D: Transcriptional regulation of cyclooxygenase-2 gene in pancreatic beta-cells. J Biol Chem 2004, 279:35403-35411.

38. Nie M, Pang L, Inoue $H$, Knox AJ: Transcriptional regulation of cyclooxygenase 2 by bradykinin and interleukin-1 beta in human airway smooth muscle cells: involvement of different promoter elements, transcription factors, and histone h4 acetylation. Mol Cell Biol 2003, 23:9233-9244. 
39. Daub H, Weiss FU, Wallasch C, Ullrich A: Role of transactivation of the EGF receptor in signalling by G-proteincoupled receptors. Nature 1996 379:557-560.

40. Kozikowski AP, Sun H, Brognard J, Dennis PA: Novel PI analogues selectively block activation of the pro-survival serine/threonine kinase Akt. J Am Chem Soc 2003, 125:1144-1145.

41. Shaulian E, Karin M: AP-1 as a regulator of cell life and death. Nat Cell Biol 2002, 4:E131-E136.

42. Mukai H, Munekata E, Higashijima T: G protein antagonists. A novel hydrophobic peptide competes with receptor for $\mathrm{G}$ protein binding. J Biol Chem 1992, 267:16237-16243.

43. Park S, Song JS, Lee DK, Yang CH: Suppression of AP-1 activity by tanshinone and cancer cell growth inhibition. Bull Korean Chem Soc 1999, 20:925-928.

44. Lund AK, Lucero J, Lucas S, Madden MC, McDonald JD, Seagrave JC Knuckles TL, Campen MJ: Vehicular emissions induce vascular MMP-9 expression and activity associated with endothelin-1-mediated pathways. Arterioscler Thromb Vasc Biol 2009, 29:511-517.

45. Song HJ, Min YS, Shin CY, Jeong JH, Sohn UD: Activation of p38 MAPK is involved in endothelin-1-stimulated COX-2 expression in cultured feline esophageal smooth muscle cells. Mol Cells 2006, 22:44-50.

46. De Lagausie P, de Buys-Roessingh A, Ferkdadji L, Saada J, Aisenfisz S, Martinez-Vinson C, Fund X, Cayuela JM, Peuchmaur M, Mercier JC, Berrebi D: Endothelin receptor expression in human lungs of newborns with congenital diaphragmatic hernia. J Pathol 2005, 205:112-118.

47. Luttrell LM, Della Rocca GJ, van Biesen T, Luttrell DK, Lefkowitz RJ: GßY subunits mediate Src-dependent phosphorylation of the epidermal growth factor receptor, A scaffold for $\mathrm{G}$ protein-coupled receptormediated Ras activation. J Biol Chem 1997, 272:4637-4644.

48. Liebmann C: Regulation of MAP kinase activity by peptide receptor signalling pathway: paradigms of multiplicity. Cell Signal 2001, 13:777-785.

49. Wetzker R, Böhmer FD: Transactivation joins multiple tracks to the ERK/ MAPK cascade. Nat Rev Mol Cell Biol 2003, 4:651-657.

50. Ji RR: Peripheral and central mechanisms of inflammatory pain, with emphasis on MAP kinases. Curr Drug Targets Inflamm Allergy 2004, 3:299-303.

51. Hsieh HL, Wu CB, Sun CC, Liao CH, Lau YT, Yang CM: Sphingosine-1phosphate induces COX-2 expression via PI3K/Akt and p42/p44 MAPK pathways in rat vascular smooth muscle cells. J Cell Physio/ 2006, 207:757-766.

52. Kalmes A, Vesti BR, Daum G, Abraham JA, Clowes AW: Heparin blockade of thrombin-induced smooth muscle cell migration involves inhibition of epidermal growth factor (EGF) receptor transactivation by heparinbinding EGF-like growth factor. Circ Res 2000, 87:92-98.

53. Wang H, Ubl JJ, Stricker R, Reiser G: Thrombin (PAR-1)-induced proliferation in astrocytes via MAPK involves multiple signaling pathways. Am J Physiol Cell Physiol 2002, 283:C1351-C1364.

54. Bobe R, Yin X, Roussanne MC, Stepien O, Polidano E, Faverdin C, Marche P: Evidence for ERK $1 / 2$ activation by thrombin that is independent of EGFR transactivation. Am J Physiol Heart Circ Physiol 2003, 285:H745-H754.

55. Kim Y, Fischer SM: Transcriptional regulation of cyclooxygenase-2 in mouse skin carcinoma cells. Regulatory role of CCAAT/enhancer-binding proteins in the differential expression of cyclooxygenase- 2 in normal and neoplastic tissues. J Biol Chem 1998, 273:27686-27694.

56. Wang HH, Hsieh HL, Yang CM: Calmodulin kinase II-dependent transactivation of PDGF receptors mediates astrocytic MMP-9 expression and cell motility induced by lipoteichoic acid. J Neuroinflammation 2010, 7:84.

57. Park SA, Kim EH, Na HK, Surh YJ: KG-135 inhibits COX-2 expression by blocking the activation of JNK and AP-1 in phorbol ester-stimulated human breast epithelial cells. Ann N Y Acad Sci 2007, 1095:545-553.

58. Tung WH, Lee IT, Hsieh HL, Yang CM: EV71 induces COX-2 expression via c-Src/PDGFR/PI3K/Akt/p42/p44 MAPK/AP-1 and NF-KB in rat brain astrocytes. J Cell Physiol 2010, 224:376-386.

Cite this article as: Hsieh et al: c-Src-dependent EGF receptor

\section{Submit your next manuscript to BioMed Central and take full advantage of:}

- Convenient online submission

- Thorough peer review

- No space constraints or color figure charges

- Immediate publication on acceptance

- Inclusion in PubMed, CAS, Scopus and Google Scholar

- Research which is freely available for redistribution 